\title{
Fitobezoara Bağlı Mekanik Bağırsak Obstrüksiyonu: 3 Olgunun Sunumu
}

\author{
Intestinal Obstruction Due To Phytobezoars Report of 3 Cases
}

\section{Cihangir Akyol', Erkinbek Orozakunov1', Salim Illksen Bașçeken1', Șiyar Ersöz1', Egemen Çiçek ${ }^{1}$, Bülent Erkek ${ }^{1}$}

\begin{abstract}
Bezoar is a stone of swallowed foreign material in the gastrointestinal tract and causes mechanic obstruction that requires surgical treatment. In this paper we are presenting 3 cases who underwent surgery. The story of gastrointestinal surgery, gastroparesy and diet habits must be examined and bezoars must be in mind in this cases.

Anahtar Sözcükler: Ileus, Bezour, Mide Cerrahisi, Gastroparezi

Bezoarlar, gastrointestinal sistem tarafından sindirilemeyerek kitle haline gelen, sıklıkla mide ve ince bağırsakta olușup, nadiren mekanik tıkanıklığa neden olarak cerrahi girișim gerektiren olușumlardır. $\mathrm{Bu}$ sunumda kliniğimize bașvuran, akut karın bulguları olan üç hasta retrospektif olarak değerlendirilmiștir. Geçirilmiș gastrik cerrahi, gastroparezi riskini arttıran durumlar ve diyet alıșkanlıkları sorgulanarak, mekanik ileus olgularında etkenin bezoar olabileceği göz önünde bulundurulmalıdır.

Key Words: Ileus, Bezoar, Stomach Surgery, Gastroparesis
\end{abstract}

Bezoarlar sindirilemeyen maddelerin gastrointestinal sistem içerisinde birikerek birleșmeleri ve katılașmaları olarak tanımlanabilir. Siklıkla midede görülmekle birlikte ince bağırsakta da görülüp mekanik tıkanıklığa neden olabilmektedirler. Bitkisel

besinlere bağlı olarak fitobezoar, saç ve kıllara bağlı olarak trikobezoar, ilaçlara bağlı olarak farmakobezoar ve infantlarda süt tozlarına bağlı olarak laktobezoar adı verilerek dört tipi bulunmaktadır.(1,2) Tüm intestinal tıkanıklıkların \% 0.4- 4 'ü bezoarlara bağlıdır.(3,4) En sık fitobezoar nedeni yiyecekler arasında ülkemizde Trabzon Hurmasi ad1 da verilen persimmon, kereviz, kabak, üzüm, kuru erik, kuru üzüm, pirasa ve pancar gelmektedir. $\mathrm{Bu}$ bitkilerin hepsi sindirilemeyen liflere sahiptir. Etiyolojide en önemli risk faktörü bu tür besinlerin aşırı tüketilmesidir. Hazırlayıcı faktörler ise değiştirilmiş mide anatomisi ve gastroparezidir. Gastroparezi en sık geçirilmiş gastrik cerrahi sonrası görülür ve hastaların \%70-94'ü bu gruptadır. Nedeni bozulan gastrik motilite, gecikmiş gastrik boşalma, azalmış asit aktivitesi ve midenin zayıflamıș karıștırma mekanizmalarıdır. En sık görülen gastroparezi nedenleri; diabetes mellitus, son dönem böbrek yetmezliğinde hemodializ ve mekanik ventilatör ihtiyacı olan hastalardı(5-7).

Tanı konulduktan sonra konservatif tedaviler ve endoskopik yaklașimlar denenebilir. Ancak tedavi çoğunlukla cerrahidir.(4,5) Yakın zamanda kliniğimize başvuran 3 olguda fitobezoarlarin her ne kadar nadir olarak görülseler de aklımızda bulunmas1 gereken bir ileus nedeni olduğunu vurgulamak istedik.

\section{OLGU 1}

İki gündür bulantı, kusma, gaz-gaita çıkaramama ve kramp tarzında karın ağr1s1 şikayetleri ile acil servise başvuran 63 yaşında erkek hastanın Özgeçmişinde 30 yıl önce peptik ülser nedeniyle geçirilmiş subtotal gastrektomi ve 10 sene önce laparoskopik kolesistektomi hikayesi 
mevcuttu. Hastanin fizik muayenesinde karında hassasiyet ve defans mevcuttu. Hiperdinamik bağırsak sesleri bulunmaktayd. Laboratuvar tetkiklerinde; lökositoz (Beyaz Küre: 15.000) ve ayakta direkt karın grafisinde hava-siv1 seviyeleri mevcuttu. Yapilan abdominopelvik bilgisayarlı tomografi incelemesinde, ince bağırsak anslarında en geniş yerinde 4 cm ölçülen kalibrasyon artışı ve mesane üst sol yan komşuluğunda izlenen geniş ileal ans içerisinde $37 \times 21 \mathrm{~mm}$ boyutta yăg dansiteleri içeren hipodens oluşum izlendi. Hastaya laparatomi yapıldi ve terminal ileumda lümeni tam olarak tikayan $4 \times 3 \mathrm{~cm}$ ve bunun $10 \mathrm{~cm}$ distalinde $3 \times 2 \mathrm{~cm}$ boyutlarında olmak üzere iki adet bezoar, el ile lümen dişından ezilerek çekuma ilerletilmeye çalışıldı ancak çok sert olması nedeniyle ilerletilemedi (Resim 1). Bunun üzerine lümeni tam obstrükte eden bezoar üzerinden enterotomi yapilarak her iki bezoarda bu açıklıktan çıkartıldı (Resim 2). Hasta ameliyat sonrası 4. gün taburcu edildi.

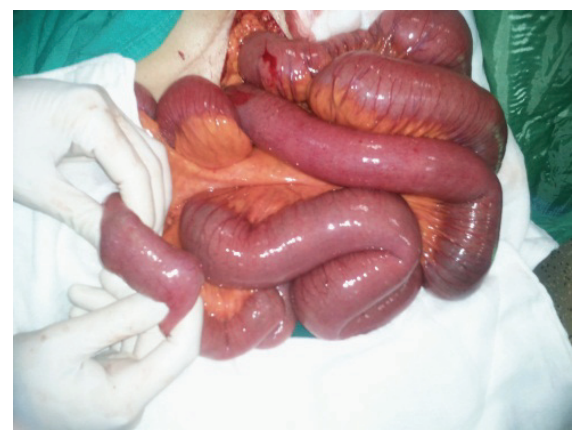

Şekil 1:Terminal ileumda saptanan bezoar çekuma ilerletilemesi

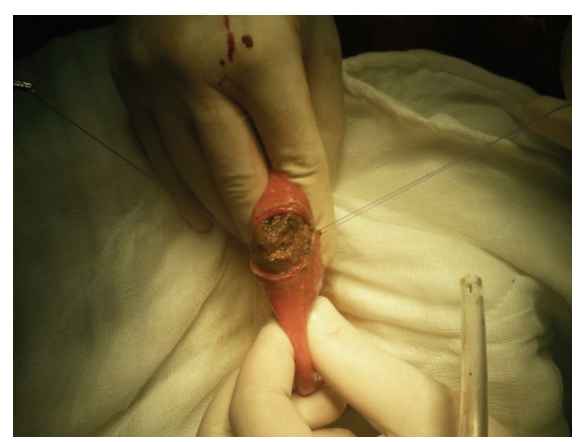

Şekil 2:Enterotomi ile bezoarlarincebarsak dışına alındı

\section{OLGU 2}

76 yaşında erkek hasta 4 gündür bulantı, kusma, karın ağrısı ve gaz-gaita çıkaramama şikayetleri ile başvurdu. Geçirilmiş karın cerrahisi ve eşlik eden hastalığ1 yoktu. Hastanın fizik muayenesinde karında yaygin hassasiyet ve defans mevcuttu. Hiperdinamik bağırsak sesleri alındı. Tam kan sayımı ve biyokimyasal parametreleri normaldi. Ayakta direk karin grafisinde hava sivi seviyeleri mevcuttu. Abdominopelvik BT'de midede dilatasyon, mide lümeni içerisinde bezoar ile uyumlu kitle, ileal anslarda belirgin olmak üzere bağırsak segmentlerinde dilatasyon ve ileumda dolma defekti izlendi. Hastaya laparatomi yapildı. Bağırsakların ileri derecede hiperemik ve ödemli olduğu görüldü. Ileumda bezoar tespit edildi. Dişarıdan mekanik olarak parçalanıp dekompresyon yapıldi. Ardindan gastrotomi yapilıp midedeki bezoar çıkarıldı ve mide duvarı onarıldı. Hasta ameliyat sonrası 6. günde taburcu edidi.

\section{OLGU 3}

66 yaşında erkek hasta 10 gün önce başlayan, yaygın karın ağrisı ve 4 gündür gaz-gaita ç1karamama şikayetleri ile acil servise başvurdu. Hastanın otuz yıl önce peptik ülser nedeniyle antrektomi ve bir y1l önce bezoar nedeni entorotomi öyküsü mevcuttu. Hastanin muayenesinde fizik muayenesinde karında hassasiyet, defans ve rebaund tespit edildi. Hiperdinamik bağırsak sesleri alındi. Ayakta direk karın grafisinde hava sivi seviyeleri mevcuttu. Yapilan tam kan sayım1 biyokimyasal parametrelerinde anormal bulgu saptanmadi. Yapilan Abdominopelvik BT incelemesinde ince bağırsak ansları en geniş yerinde $4,5 \mathrm{~cm}$ olan dilatasyon izlendi. Obstrüksiyon proksimalinde ki barsak ansları ileri derecede geniş izlenmiş olup duvarları kalındı. Aynı zamanda peritoneal serbest siv1 izlendi (Resim 3). Hastaya ileus nedeniyle laparotomi yapild1 ve distal ince bagirsakta bezoar saptandi. Enterotomi ile bezoar çıartıldı. Hasta postoperatif 4. günde taburcu edildi.

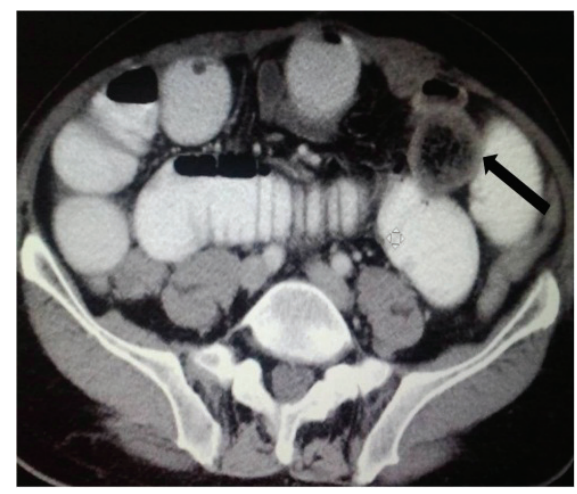

Şekil 3:Bilgisayarlı tomografide ileumda bezoara ait intestinal obstrüksiyon

\section{TARTIȘMA}

Fitobezoarlar, sindirime uğramayan bitkisel besin liflerinin taşlaşması olarak tanımlanabilir. Mekanik intestinal obstrüksiyonun nadir görülen sebeplerinden biridir. Gastrik cerrahiyi takiben \%5-12 s1klikta bezoar oluşabildiği bildirilmiştir (8). Trunkal vagotomi uygulanan mide ameliyatlarından sonra hem mide motilitesi hem de asit sekresyonu azalmaktadır. $\mathrm{Bu}$ durum midede bezoar oluşumuna zemin hazırlamaktadır (9). Bizim olgularımızın ikisinde geçirilmiş gastrik cerrahi öyküsü mevcuttu. Proton pompa inhibitörlerinin rutin kullanıma girmesinden önceki dönemlerde peptik ülser tedavisi için cerrahi yöntemler daha sık kullanıldığ için, bezoarlara bağlı akut karın sendromu olgular1 daha s1k görülmekte iken günümüzde daha nadir karşılaşılan bir klinik durum haline gelmiştir. İntestinal bezoarlar da siklıkla ileumun son $70 \mathrm{~cm} \mathrm{lik}$ kısmı ve ilioçekal valv düzeyinde yerleşmektedir. Bu durum tanımlanan bağırsak ansının lümeninin daha dar ve peristaltizmin de bu bölgede daha yavaş olmasından kaynaklanmaktadır. Bununla birlikte mide operasyonu bulunmayan olgularda az çiğneme ve yüksek lifli diyetle beslenme bezoar oluşumuna yol açabilir. Diyabete bağlı gastroparezi de risk faktörlerinden biridir. (10,11). Tüm intestinal obstrüksiyonların $\% 0.4-$ 4'ünün gastrointestinal bezoarlara bağlı olduğu bildirilmektedir $(3,4)$ 
Tanıda radyolojik yöntemler oldukça önemli yer tutar. Direkt grafi ile saptanma oranlar1 \%17 iken USG ile $\% 88$ ve bilgisayarlı tomografi ile ise saptanma oranlar1 \%97'dir(12). Ancak bezoarların en çok mide de bulunması nedeniyle akut karın bulguları olmayan hastalarda altın standart yöntem endoskopidir. Olgularımızın hepsinde laparotomi gerektirecek ileus ve akut karın bulguları olduğu için endoskopik girişim düşünülmedi. Ayrıca kronik karın ağrısı ve kabızlık ile gelen hastada bezoardan şüpheleniliyorsa baryumlu grafilerden de fayda sağlanabilir.

\section{KAYNAKLAR}

1. Whitson BA, Asolati M, Kandaswamy R, et al. Diabetic gastroparesis-associated bezoar resolution via "cola-lysis". Clin Transplant. 2008; 22: 242-244.

2. Sechopoulos P, Robotis JF, Rokkas T. Gastric bezoar treated endoscopically with a carbonated beverage: case report. Gastro-intest Endosc 2004; 60: 662-664

3. Vitellas KM, Vaswani K, Bennett WF. Case 2. Small-bowel bezoar. AJR Am J. Roentgenol. 2000; 175: 873; 876-878.

4. Ripollés T, García-Aguayo J, Martínez MJ, et al. Gastrointestinal bezoars: sonographic and CT characteristics. AJR Am J Roentgenol. 2001; 177: 65-69.
Akut karın bulguları olmayan bezoara bağlı ileus olgularında ilk olarak konservatif tedavi denenmelidir. Bunlar; nazogastrik dekompresyon, prokinetik ajanlar(metokloropamid gibi), iv hidrasyon ve selüloz gibi ayrıştırıcı ajanlardır. $\mathrm{Bu}$ tedavilerin sonuç vermemesi halinde hastalara cerrahi girişim uygulanmalıdır. Ameliyata bağlı riskler kanama, perforasyon ve ameliyat sonras1 yapışıklıklara bağlı obstrüksiyonlardır. Bizim olgularımız konservatif tedaviye cevap vermediği için ameliyat kararı alınmıştır.

5. Ayten R., Çetinkaya Z., Aygen E., ve ark. Mental retardasyonlu olguda trikobezoara bağlı nadir bir komplikasyon: izole ince barsak tıkanması. Firat Tip Dergisi 2006; 11: 83-84.

6. Rogers LF, Davis EK, Harle TS Phytobezoar formation and food boli following gastric surgery AJR 1973; 119: $280-290$.

7. Perttala $\mathrm{Y}$, Peltokallio $\mathrm{P}$, Leiviskä $\mathrm{T}$, et al. Bezoar formation following gastric surgery AJR 1975; 125: 365 - 373.

8. Cifuentes j, Robles R, Parilla P. Gastric surgery and bezoars. Dig Dis Sci 1992; 37: 1694-1696.
Hastaya laparotomi sonrası gastrik bezoarlar için gastrotomi, ince bağırsak bezoarları için enterotomi veya rezeksiyon yapilabilir. Bezoarlara gastrointestinal traktın herhangi bir yerinde rastlabileceğinden tüm gastrointestinal sistem gözden geçirilmelidir.

Bezoarlar nadir görülmelerine rağmen ileus nedenleri arasinda akılda tutulmalıdır. Özellikle geçirilmiş gastrik cerrahi, gastroparezi riskini arttıran predispozan faktörler ve diyet alışkanlıklarının iyi sorgulanması bizi tanıya yakınlaştırmalıdır.

9. Robles R, Parrilla P, Escamilla C, et al Gastrointestinal bezoars. Br J Surg. 1994; 81: 1000-1001.

10. Delabrousse E, Brunelle S, Saguet O, et al. Small bowel obstruction secondary to phytobezoar CT Findings. Clin Imaging 2001; 25: 44-46.

11. Whitson BA, Asolati M, Kandaswamy R, et al. Diabetic gastroparesis-associated bezoar resolution via "cola-lysis". Clin Transplant. 2008; 22: 242-244.

12. Yildirim T, Yildirim S, Barutcu $O$, et al. Small bowel obstruction due to phytobezoar: CT diagnosis. Eur Radiol. 2002; 12: 2659-2661. 
